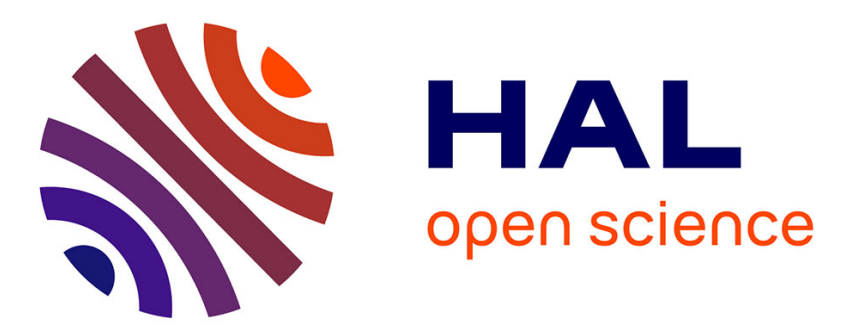

\title{
X-ray absorption spectroscopy study of buried Co layers in the $\mathrm{Co} / \mathrm{Mo} 2 \mathrm{C}$ multilayer mirrors
}

Yanyan Yuan, Karine Le Guen, Yuchun Yu, Jingtao Zhu, Zhanshan Wang, Wenbin Li, Mingwu Wen, Christian Mény, Haisheng Yu, Yuying Huang, et al.

\section{- To cite this version:}

Yanyan Yuan, Karine Le Guen, Yuchun Yu, Jingtao Zhu, Zhanshan Wang, et al.. X-ray absorption spectroscopy study of buried Co layers in the Co/Mo2C multilayer mirrors. Surface and Interface Analysis, 2017, 49 (3), pp.205 - 209. 10.1002/sia.6116 . hal-01480541

\section{HAL Id: hal-01480541 https: / hal.sorbonne-universite.fr/hal-01480541}

Submitted on 1 Mar 2017

HAL is a multi-disciplinary open access archive for the deposit and dissemination of scientific research documents, whether they are published or not. The documents may come from teaching and research institutions in France or abroad, or from public or private research centers.
L'archive ouverte pluridisciplinaire HAL, est destinée au dépôt et à la diffusion de documents scientifiques de niveau recherche, publiés ou non, émanant des établissements d'enseignement et de recherche français ou étrangers, des laboratoires publics ou privés. 


\title{
X-ray absorption spectroscopy study of buried Co layers in the $\mathrm{Co} / \mathrm{Mo}_{2} \mathrm{C}$ multilayer mirrors
}

\author{
Yanyan Yuan ${ }^{1,2^{*}}$, Karine Le Guen ${ }^{1,2}$, Yuchun Tu ${ }^{1,2,3}$, Jingtao Zhu ${ }^{3}$, Zhanshan Wang ${ }^{3}$, Wenbin Li ${ }^{3}$, Mingwu Wen ${ }^{3}$, \\ Christian Mény ${ }^{4}$, Haisheng Yu ${ }^{5}$, Yuying Huang ${ }^{5}$, Xiangjun Wei ${ }^{5}$, Philippe Jonnard ${ }^{1,2}$ \\ ${ }^{\text {l} S o r b o n n e ~ U n i v e r s i t e ́ s, ~ U P M C ~ U n i v ~ P a r i s ~ 06, ~ L a b o r a t o i r e ~ d e ~ C h i m i e ~ P h y s i q u e-M a t i e ̀ r e ~ e t ~ R a y o n n e m e n t, ~}$ \\ 11 rue Pierre et Marie Curie, F-75231 Paris cedex 05, France \\ 2 CNRS UMR 7614, Laboratoire de Chimie Physique-Matière et Rayonnement, 11 rue Pierre et Marie Curie, F-75231 Paris cedex 05, France \\ ${ }^{3}$ Institute of Precision Optical Engineering, Department of Physics, Tongji University, Shanghai 200092, China \\ ${ }^{4}$ Institut de Physique et Chimie des Matériaux de Strasbourg, UMR 7504 CNRS-Université De Strasbourg 23 rue du Loess, 67034 Strasbourg, France \\ ${ }^{5}$ Shanghai Synchrotron Radiation Facility, Shanghai Institute of Applied of Physics Chinese Academy of Sciences, Zhangheng Road 239, Pudong, \\ Shanghai 201204, China
}

\begin{abstract}
X-ray absorption spectroscopy (XAS) at the Co K edge was applied to investigate the chemical environment of $\mathrm{Co}$ atoms inside $\mathrm{Co} / \mathrm{Mo}_{2} \mathrm{C}$ periodic multilayers. The results show a mixing between $\mathrm{Co}$ and $\mathrm{Mo}_{2} \mathrm{C}$ layers prior to any annealing process whereas following annealing from $300^{\circ} \mathrm{C}$ pure Co layers are observed. XAS results are in agreement with previous nuclear magnetic resonance spectroscopy results. They indicate that the pure Co content increases upon annealing, while it is absent in the as-deposited samples. The comparison of the results, based on the analysis of the data obtained on the multilayer samples and some reference materials, reveals that the ordering of Co atoms inside the Co layers increases upon annealing.
\end{abstract}

Keywords: XANES; EXAFS; interface analysis; periodic multilayer; buried Co layers; annealing

\footnotetext{
* Corresponding author: e-mail: yuan.yanyan@just.edu.cn. The present address of author Yanyan Yuan is School of Materials Science and Engineering, Jiangsu University of Science and Technology, Mengxi Road 2, Zhenjiang, Jiangsu Province, 212003, China. The present address of author Yuchun Tu is Shanghai Institute of Laser Plasma, Chenjiashan Road 1129, Jiading district, Shanghai, 201800, China.
} 


\section{Introduction}

Multilayer structures consisting of a periodic alternation of thin films show a variety of interesting properties and applications. They provide not only the potential applications as X-ray and neutron optical elements but also convenient tools for studying the interfaces between different materials. The accurate characterization of interfaces in multilayer structures is still a challenging task and is very important for the improvement of their application properties[1], [2].

$\mathrm{X}$-ray absorption spectroscopy (XAS) is well known for probing the local atomic structure around a specific element in thin films and other structures [3]-[8]. In the case of buried interfaces, the phases are often formed in a narrow region, are highly disordered or present a short-range order. Thus the XAS technique with short-range order sensitivity provides a powerful tool for the study of interface phases, also called interphases. Examples of XAS investigation of multilayered samples can be found in [9]-[14].

The interfacial properties of the $\mathrm{Co} / \mathrm{Mo}_{2} \mathrm{C}$ multilayer have been studied in a previously published paper [15]. It reported that the $\mathrm{Co}$ and $\mathrm{C}$ atoms mix together during deposition and then, following annealing from $300^{\circ} \mathrm{C}$, Co and $\mathrm{C}$ demix from their mixed regions. In order to interpret the chemical bond environment of Co layers upon annealing, XAS was measured by detecting the fluorescence radiation. Both XANES (X-ray absorption near edge spectroscopy) and EXAFS (extended X-ray absorption fine structure) spectra were used.

\section{Experiment}

The $\mathrm{Co} / \mathrm{Mo}_{2} \mathrm{C}$ multilayer samples were prepared by magnetron sputtering. Three different samples are considered: as-deposited, annealed at 300 and $600^{\circ} \mathrm{C}$ in a furnace for $1 \mathrm{~h}$ with a pressure of $3.0 \times 10^{-4} \mathrm{~Pa}$, respectively. The details of sample preparation were given previously [16]. Here we recall only the structure of the samples: the thickness of Co and $\mathrm{Mo}_{2} \mathrm{C}$ layer in one period is 2.6 and $1.5 \mathrm{~nm}$, respectively; the number of period is 30; the substrates are sliced and polished Si (100) wafers. A 3.5-nm-thick $\mathrm{B}_{4} \mathrm{C}$ capping layer is deposited onto the multilayer top to prevent oxidation. Table 1 lists the structural parameters of these samples derived from the x-ray reflectivity data measured at $0.154 \mathrm{~nm}$ [16]. Those values will be used in the following sections. Different 
characterization methods have been carried out such as x-ray reflectometry in the hard and soft x-ray ranges, $\mathrm{x}$-ray emission spectroscopy, nuclear magnetic resonance (NMR) spectroscopy whose results were given elsewhere [15], [17].

The XAS experiments were carried out at beam line BL14W1 at the Shanghai synchrotron radiation facility [18]. Two types of double crystal monochromators are used for covering photon energy range from 4.5 to $50 \mathrm{keV}$. The photon energy Resolution $(\Delta \mathrm{E} / \mathrm{E})$ is around $10^{-4}$. The multilayers deposition onto thick substrates leads to the impossibility of absorption measurements in transmission, fluorescence detection was used in this study. The XAS experiment is made in the partial fluorescence yield mode, where the integrated intensity of the Co K $\alpha$ characteristic emission is measured as a function of the energy of the incident radiation scanned through the Co $\mathrm{K}$ edge (7709 eV). A 32-element Canberra/XIA Ge detector system was used to detect the fluorescence radiation.

For the sake of comparison, the XAS spectra of some reference samples (CoMo ( 1 at.\%), $\mathrm{Co}_{3} \mathrm{Mo}$, $\mathrm{Co}_{3} \mathrm{Mo}_{3} \mathrm{C}$ and $\mathrm{Co}_{6} \mathrm{Mo}_{6} \mathrm{C}$ solid solutions and a $\mathrm{Co}$ foil) were also obtained. Here, the spectra of the reference samples CoMo (1 at.\%), $\mathrm{Co}_{3} \mathrm{Mo}, \mathrm{Co}_{3} \mathrm{Mo}_{3} \mathrm{C}$ and $\mathrm{Co}_{6} \mathrm{Mo}_{6} \mathrm{C}$ solid solutions were obtained in fluorescence mode and that of the Co foil in transmission mode. We should keep in mind that the direct comparison of the intensity of the features of the multilayers and the reference samples is difficult as the self-absorption conditions are not the same in thin films and bulk materials.

All the XAS spectra were normalized after a background subtraction taking into account the low and high photon energy parts of the spectra far from the threshold. This was done with the IFEFFIT software [19]. The background toward the high energy side can be difficult to determine owing to the presence of the first EXAFS oscillations, leading to an uncertainty on the intensity near the threshold.

\section{Results and discussion}

Fig. 1(a) and (b) respectively show the EXAFS and XANES spectra in the vicinity of the Co K edge of the three $\mathrm{Co} / \mathrm{Mo}_{2} \mathrm{C}$ multilayer samples and the Co foil reference. All the spectra present a shoulder at about $7713 \mathrm{eV}$, whose value is determined by the minimum of the first derivative. The spectra of the annealed multilayers exhibit higher-contrasted oscillations and are close to those of the Co reference. This indicates that the local environment of the Co atoms in the annealed multilayer is 
similar to that of Co atoms in the Co foil. In the case of the as-deposited sample, the oscillations are attenuated, especially above $7850 \mathrm{eV}$.
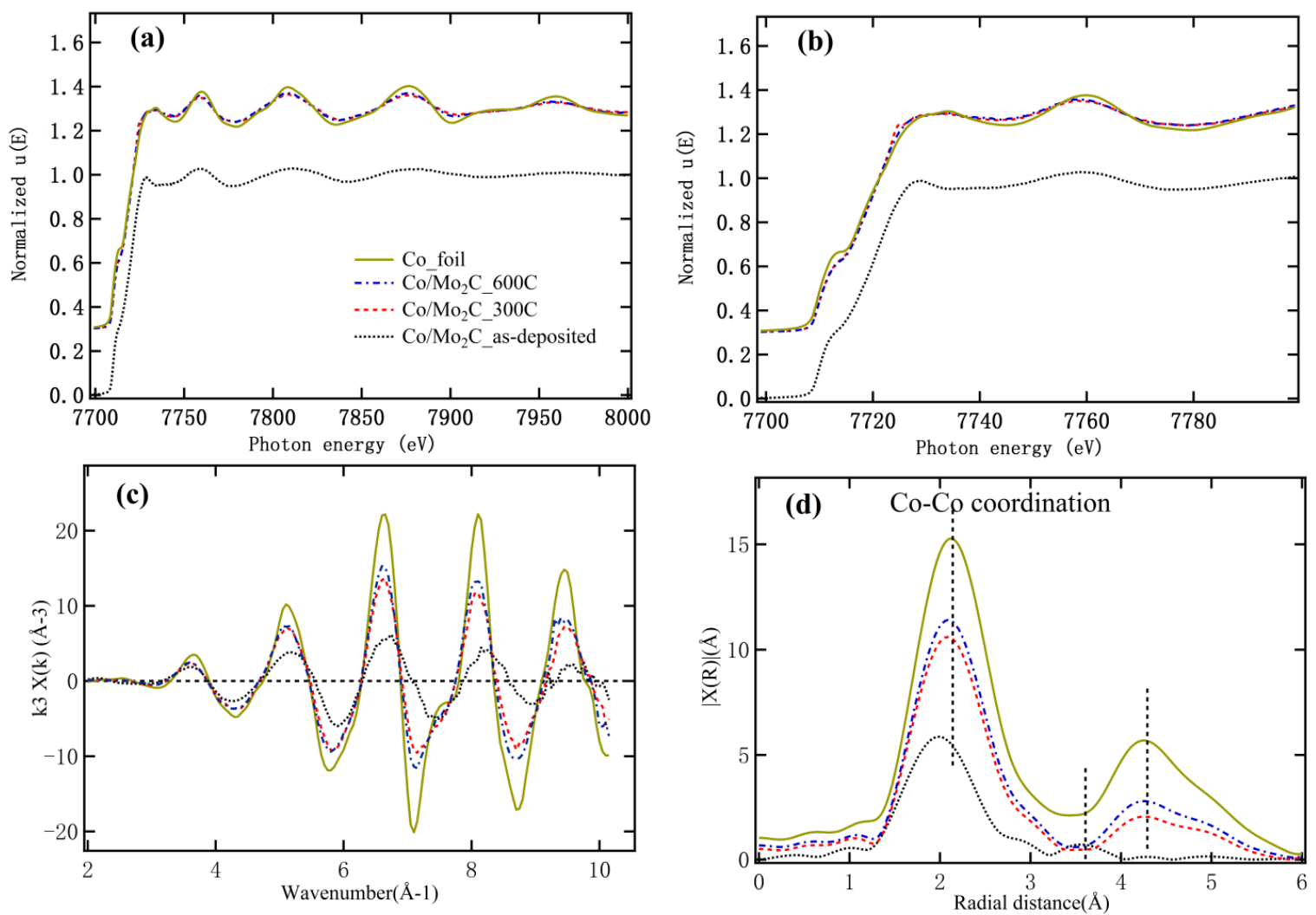

Fig. 1: Co K edge $\mathrm{x}$-ray absorption measurement of the $\mathrm{Co} / \mathrm{Mo}_{2} \mathrm{C}$ multilayers (as-deposited, annealed at 300 and $600^{\circ} \mathrm{C}$ ), and the Co foil reference: (a) normalized EXAFS spectra; (b) normalized XANES spectra; (c) $k^{3}$-weighted k-space spectra and (d) Fourier transform R-space spectra of EXAFS. For the sake of clarity, curves are vertically shifted in (a) and (b).

Fig. 1(c) and (d) respectively show, for the three multilayers and the reference, the $k^{3}$-weighted $\mathrm{k}$-space spectra (data have been multiplied by $k^{3}$ to enhance the oscillations at high $k$ ) and Fourier transform R-space spectra (the Fourier transform of an EXAFS spectrum would give a similar radial distribution function) of the EXAFS data. In all spectra, the highest contrast is obtained for the Co foil. The $k^{3}$-weighted k-space spectra of the multilayer present well-contrasted oscillations for high $k$ values. The amplitude of the oscillations increases as a function of the annealing temperature. The same trend can be seen on the Fourier transform R-space spectra, Fig. 1(d). 


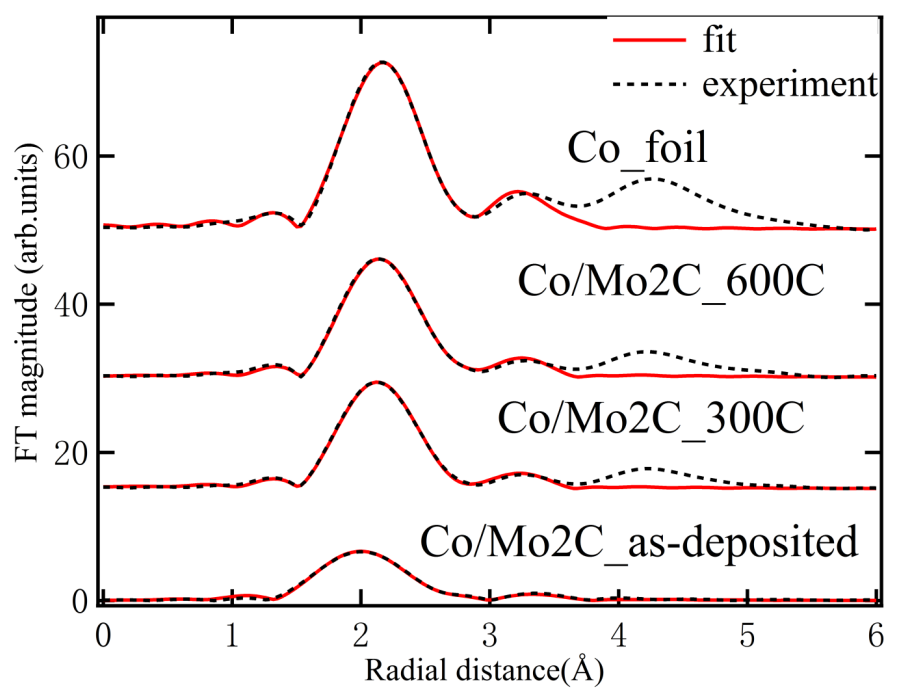

Fig. 2: The $k^{3}$ weighted Fourier transforms of the Co K-edge EXAFS spectra $\left(k=3\right.$ to $\left.10.15 \AA^{-1}\right)$ measured on the $\mathrm{Co} / \mathrm{Mo}_{2} \mathrm{C}$ multilayers (as-deposited, annealed at 300 and $600^{\circ} \mathrm{C}$ ), and the Co foil reference. The fits were carried out in R-space in the interval of $([1.0,5.0] \AA)$. For the sake of clarity, curves are vertically shifted.

Quantitative analysis of EXAFS spectra is performed to determine the local environment information of $\mathrm{Co}$ atoms: coordination number, atoms bond length. A hexagonal $\mathrm{Co}_{3} \mathrm{Mo}$ phase (space group P63 $/ \mathrm{mmc}$, lattice parameters $a=5.1245 \mathrm{~nm}, b=5.1245 \mathrm{~nm}, c=4.1125 \mathrm{~nm}$ [20]) was used. In the fit procedure we introduced the parameters: amplitude reduction factor $S_{0}^{2}$, zero energy shift $\Delta E_{0}$, atoms bond length $\mathrm{R}$, Debye-Waller factors $\sigma^{2}$. Four single scattering paths of Co atoms were used and yield an excellent fit for the region from 1.0 to $5.0 \AA$. In four single scattering paths, the amplitude reduction factor $S_{0}^{2}$ and zero energy shift $\Delta E_{0}$ are defined to be consistent for each scattering path, the bond length $\mathrm{R}$ are defined independent, the Debye-Waller factors $\sigma^{2}$ of the first path are independent and others are be consistent.

The best fit is obtained with the hexagonal $\mathrm{Co}_{3} \mathrm{Mo}$ phase theoretical model for the $\mathrm{Co} / \mathrm{Mo}_{2} \mathrm{C}$ multilayers (as-deposited, annealed at 300 and $600^{\circ} \mathrm{C}$ ), shown in Fig. 2. A good fit is obtained in the $\mathrm{R}$ range of $[1.0,5.0] \AA$ for the $\mathrm{Co} / \mathrm{Mo}_{2} \mathrm{C}$ as-deposited sample and that of the other samples are in the interval of $[1.0,3.5] \AA$. This indicates that the local structure of Co atoms in the multilayers sample is close to that of the hexagonal $\mathrm{Co}_{3} \mathrm{Mo}$ phase. The Co-Co coordination number of the first shell is obtained using four single scattering paths. Best fit values of the parameters are listed in Table 2 for the first shell. The results show that the coordination number of the first shell increases with the annealing temperature. The Debye-Waller factors $\sigma^{2}$ are decreasing, indicating the strong ordering of Co atoms upon annealing. The same results were reported by Chernov et al. in the $\mathrm{Co} / \mathrm{C}$ 
multilayer [10]. From the structural parameters of the EXAFS fit however it is not possible to determine if the $\mathrm{Co}_{3} \mathrm{Mo}$ phase is fully formed or if only sub-scale crystallites are formed at the interfaces of the multilayer. We can only say that the local structure around the Co atoms is similar but not equal to the one in the $\mathrm{Co}_{3} \mathrm{Mo}$ hep phase.

In order to better understand the structure of the multilayer samples, the XAS spectra of the references, namely the CoMo (1 at.\%), $\mathrm{Co}_{3} \mathrm{Mo}, \mathrm{Co}_{3} \mathrm{Mo}_{3} \mathrm{C}$ and $\mathrm{Co}_{6} \mathrm{Mo}_{6} \mathrm{C}$ solid solutions, are presented in Fig. 3 compared to the one of the Co foil. Here self-absorption correction of XAS spectra has been performed for the thick samples. In Fig. 3(a) and 3(b), the oscillations in the spectra of the solid solutions are poorly contrasted with respect to those of the pure Co foil reference, except that of the CoMo (1 at.\%). The first maximum is reported at $7730 \mathrm{eV}$ for the $\mathrm{Co}_{3} \mathrm{Mo}, \mathrm{Co}_{3} \mathrm{Mo}_{3} \mathrm{C}$ and $\mathrm{Co}_{6} \mathrm{Mo}_{6} \mathrm{C}$ solid solutions and $7734 \mathrm{eV}$ for the Co foil and CoMo (1 at.\%). The second and third ones are located at 7754 and $7803 \mathrm{eV}$ respectively for the $\mathrm{Co}_{3} \mathrm{Mo}, \mathrm{Co}_{3} \mathrm{Mo}_{3} \mathrm{C}$ and $\mathrm{Co}_{6} \mathrm{Mo}_{6} \mathrm{C}$ solid solution samples while they are located at 7760 and $7808 \mathrm{eV}$ respectively for bulk Co and CoMo (1 at.\%). Near the edge, all spectra present a shoulder, whose intensity and positions vary depending on the sample (and on the self-absorption conditions). The shoulder position of the Co foil and CoMo (1 at.\%) is located at around $7715 \mathrm{eV}$ and around $7716 \mathrm{eV}$ for the other samples. The shift is due to the change of Co oxidation state.

In Fig. 3(c), the spatial frequency in the $k^{3}$-weighted k-space spectra slightly differs from one sample to another. In Fig. 3(d), the $\mathrm{Co}_{3} \mathrm{Mo}, \mathrm{Co}_{3} \mathrm{Mo}_{3} \mathrm{C}$ and $\mathrm{Co}_{6} \mathrm{Mo}_{6} \mathrm{C}$ show a weak coordination sphere peak corresponding to that of the Co foil. A closer examination of the R-space spectra of the $\mathrm{Co}_{3} \mathrm{Mo}_{3} \mathrm{C}$ and $\mathrm{Co}_{6} \mathrm{Mo}_{6} \mathrm{C}$ samples shows a shoulder toward the high radial distances, close to the first coordination sphere, which is located in between the first and second Co-Co coordination spheres of the Co foil. This indicates a local ordering trend of $\mathrm{Co}$ atoms inside the $\mathrm{Co}_{3} \mathrm{Mo}_{3} \mathrm{C}$ and $\mathrm{Co}_{6} \mathrm{Mo}_{6} \mathrm{C}$ samples. 

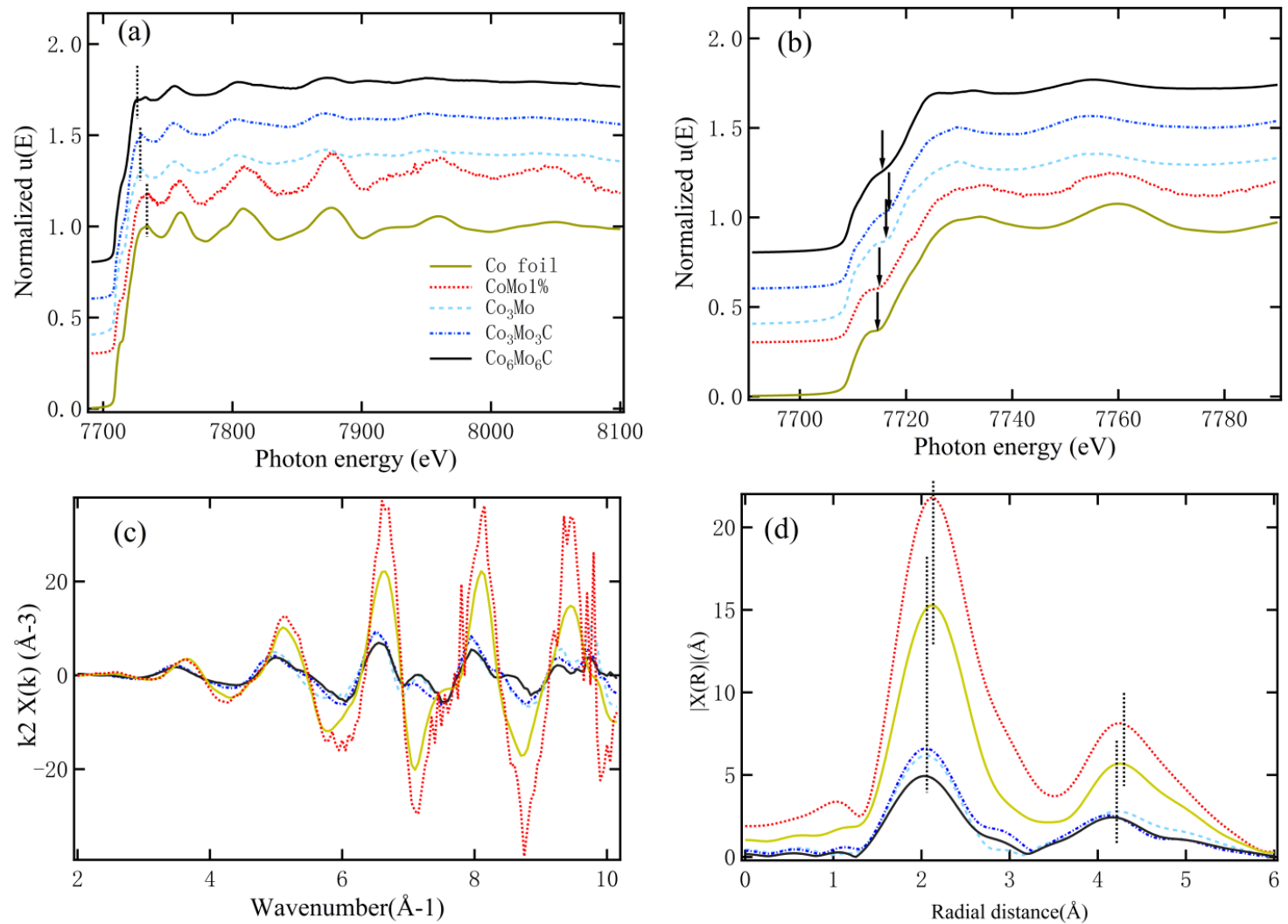

Fig. 3: Co K edge x-ray absorption measurement of the solid solution references, CoMo (1 at.\%), $\mathrm{Co}_{3} \mathrm{Mo}_{,} \mathrm{Co}_{3} \mathrm{Mo}_{3} \mathrm{C}$ and $\mathrm{Co}_{6} \mathrm{Mo}_{6} \mathrm{C}$, compared to the Co foil: (a) normalized EXAFS spectra; (b) normalized XANES spectra; (c) $k^{3}$-weighted k-space spectra and (d) Fourier transform R-space spectra of EXAFS data. For the sake of clarity, curves are vertically shifted in (a) and (b).

In order to obtain further details on the chemical bond of the Co atoms within the multilayers, we compared in Fig. 4 the Co K edge XAS spectra of two references (Co foil and $\mathrm{Co}_{3} \mathrm{Mo}_{3} \mathrm{C}$ ) and two multilayers (as-deposited and annealed at $600^{\circ} \mathrm{C}$ ). In Fig. 4(a), the positions of the observed features for the as-deposited sample correspond to those of the Co foil but with different relative intensities. It is clear that for the as-deposited sample there is no pure $\mathrm{Co}$ in the stack [15]. Compared to $\mathrm{Co}_{3} \mathrm{Mo}_{3} \mathrm{C}$, the as-deposited multilayer exhibits close EXAFS features, similar amplitudes but with different frequencies in the $k^{3}$-weighted $\mathrm{k}$-space spectrum, and similar low coordination numbers in the Fourier transform R-space spectra. This suggests that only the local atomic structure of the Co layer inside the as-deposited sample is similar to that of the solid solution $\mathrm{Co}_{3} \mathrm{Mo}_{3} \mathrm{C}$. It can be deduced that in the as-deposited sample the Co layers are mixed with $\mathrm{C}$ and $\mathrm{Mo}$ atoms. Concerning the $\mathrm{Co} / \mathrm{Mo}_{2} \mathrm{C}$ multilayer annealed at $600^{\circ} \mathrm{C}$, the great similarities in the EXAFS and XANES spectra with respect to the Co foil point out a similar local environment of the Co atoms. This confirms our previous 
results demonstrating that annealing leads to the ordering of the Co layer and the inherent increase of pure Co content.
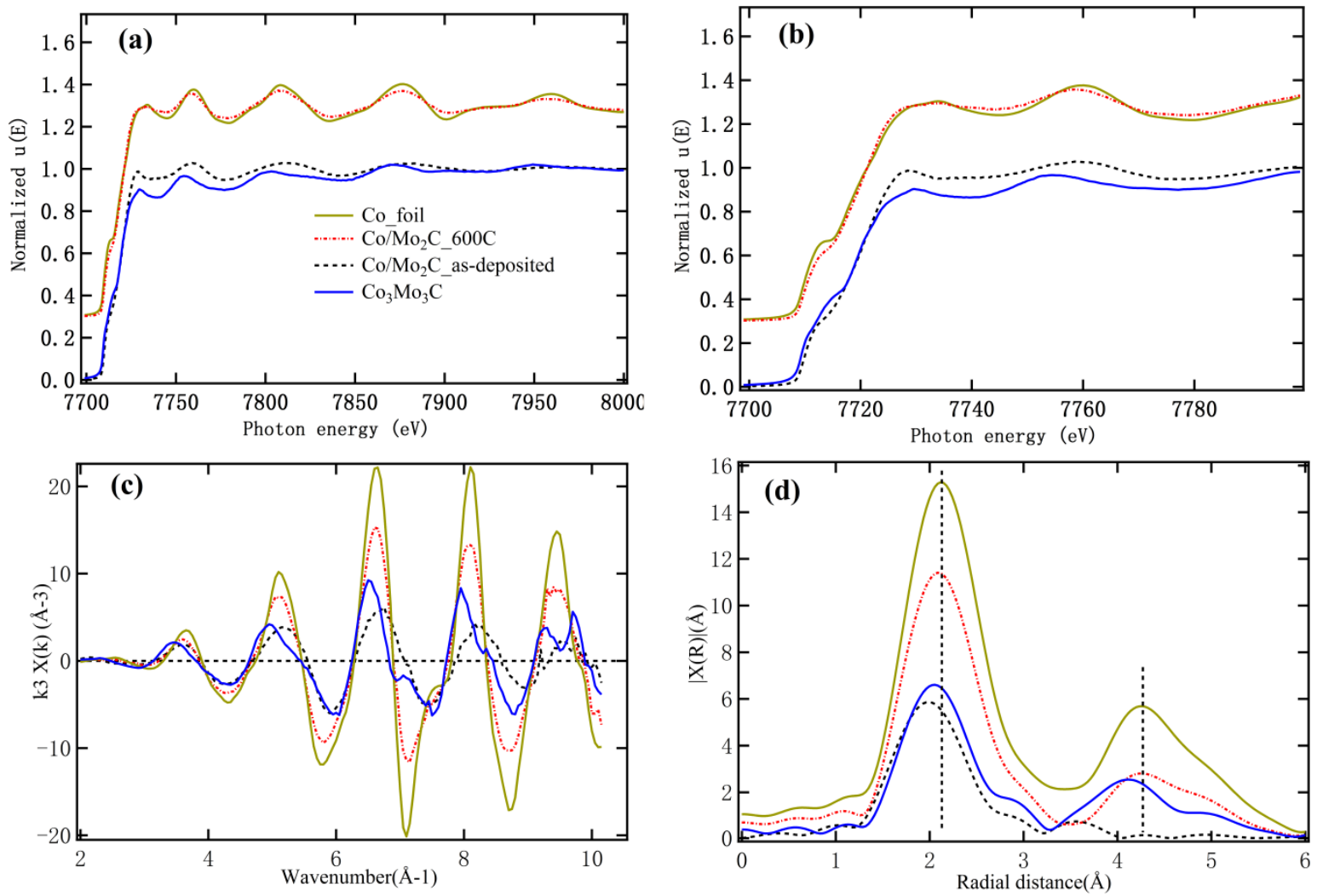

Fig. 4: Co K edge x-ray absorption measurement of two solid solution references, $\mathrm{Co}_{3} \mathrm{Mo}_{3} \mathrm{C}$ and $\mathrm{Co}_{6} \mathrm{Mo}_{6} \mathrm{C}$, and of two $\mathrm{Co} / \mathrm{Mo}_{2} \mathrm{C}$ multilayers, as-deposited and annealed at $600^{\circ} \mathrm{C}$ : (a) normalized EXAFS spectra; (b) normalized XANES spectra; (c) $k^{3}$-weighted k-space spectra and (d) Fourier transform R-space spectra of EXAFS data. For the sake of clarity, curves are vertically shifted in (a) and (b).

\section{Conclusion}

The XAS spectra of $\mathrm{Co} / \mathrm{Mo}_{2} \mathrm{C}$ multilayer samples measured in the partial fluorescence mode were carried out at the Co $\mathrm{K}$ edge. The chemical environment of the Co atoms was studied by collecting the $\mathrm{Co} \mathrm{K} \alpha$ fluorescence signal. In light of all the above results, some significant spectra have been obtained for the differently annealed samples and for the reference materials. There is a clear distinction between the as-deposited and the annealed $\mathrm{Co} / \mathrm{Mo}_{2} \mathrm{C}$ multilayer samples from the XAS spectra. This behavior is in agreement with the one measured through NMR experiments [15], where the mixing of the Co layers occurs for the as-deposited sample, whereas pure Co is observed upon annealing from $300^{\circ} \mathrm{C}$. In addition we show that both $\mathrm{Mo}$ and $\mathrm{C}$ atoms of the $\mathrm{Mo}_{2} \mathrm{C}$ layers are 
involved in the mixing with the Co atoms. Moreover the quantitative analysis of the EXAFS data indicates a stronger local ordering of the Co layers following annealing. In conclusion, with the annealing process, demixing takes place in the $\mathrm{Co}$ and $\mathrm{C}$ mixing region and the layers become ordered, which results in the existence of pure Co region in the annealed samples.

\section{Acknowledgments}

This work is done under the framework of the international ANR-NSFC COBMUL project (ANR \#10-INTB-902-01 and NSFC \#11061130549) and Natural Science Foundation of China (\#11061130549) and of the Cai Yuanpei Project (EGIDE PHC No. 30248NF), 973 program (No. 2011CB922203), and National Natural Science Foundation of China (Nos. 11375131 and 11305104).

\section{References}

[1] H. Maury, P. Jonnard, J.-M. André, J. Gautier, F. Bridou, F. Delmotte and M.-F. Ravet, Interface characteristics of $\mathrm{Mo} / \mathrm{Si}$ and $\mathrm{B}_{4} \mathrm{C} / \mathrm{Mo} / \mathrm{Si}$ multilayers using non-destructive $\mathrm{X}$-ray techniques, Surf. Sci., 2007, 601, 1, 2315-2322.

[2] Q. Zhong, W. Li, Z. Zhang, J. Zhu, Q. Huang, H. Li, Z. Wang, P. Jonnard, K. Le Guen, J.-M. André, H. Zhou and T. Huo, Optical and structural performance of the Al(1\% wtSi)/Zr reflection multilayers in the 17-19nm region, Opt. Express, 2012, 20, 10, 10692-10700.

[3] Y. Yacoby, E. A. Stern, Achievements and prospects in X-ray absorption spectroscopy, AIP Conference Proceedings, 1997; 389, 535-556.

[4] M. A. Mohiddon, K. L. Naidu, M. G. Krishna, G. Dalba, S. I. Ahmed and F. Rocca, Chromium oxide as a metal diffusion barrier layer: An x-ray absorption fine structure spectroscopy study, $J$. Appl. Phys., 2014; 115, 4, 044315.

[5] R. V. Dennis, B. J. Schultz, C. Jaye, X. Wang, D. A. Fischer, A. N. Cartwright and S. Banerjee, Near-edge x-ray absorption fine structure spectroscopy study of nitrogen incorporation in chemically reduced graphene oxide, J. Vac. Sci. Technol. B, 2013; 31, 4, 041204.

[6] K. Amemiya and M. Sakamaki, NiO-like single layer formed on a $\mathrm{Ni} / \mathrm{Cu}(001)$ thin film revealed by the depth-resolved x-ray absorption spectroscopy, Appl. Phys. Lett., 2011; 98, 1, 012501.

[7] J. Jiménez-Mier, P. Olalde-Velasco, G. Carabalí-Sandoval, G. Herrera-Pérez, E. Chavira, W.-L. Yang and J. Denlinger, X-ray absorption to determine the metal oxidation state of transition metal compounds, AIP Conference Proceedings, 2013; 1544, 78-85.

[8] H. L. Bao, X. P. Sun, Z. Jiang, Y. Y. Huang and J. Q. Wang, Structural changes of Rh-Mn nanoparticles inside carbon nanotubes studied by X-ray absorption spectroscopy, Chin. J. Catal., $2014 ; 35,8,1418-1427$.

[9] M. Rovezzi, F. D'Acapito, A. Patelli, V. Rigato, G. Salmaso, E. Bontempi and I. Davoli, Characterization of thermally treated $\mathrm{Mo} / \mathrm{Si}$ multilayer mirrors with standing wave-assisted EXAFS, Nucl. Instrum. Methods Phys. Res. Sect. B Beam Interact. Mater. At., 2006; 246, 1, $127-130$. 
[10] A. Gupta, P. Rajput and C. Meneghini, Depth-resolved x-ray absorption fine structure study of Fe/Si interfaces using x-ray standing waves, Phys. Rev. B, 2007; 76, 19, 195401.

[11] S. M. Heald and J. M. Tranquada, Standing - wave - assisted extended x-ray absorption fine-structure study of a Ni - Ti multilayer, J. Appl. Phys., 1989; 65, 1, 290-293.

[12] V. A. Chernov, N. I. Chkhalo, M. V. Fedorchenko, E. P. Kruglyakov, S. V. Mytnichenko and S. G. Nikitenko, Structural changes study of $\mathrm{Co} / \mathrm{C}$ and $\mathrm{Ni} / \mathrm{C}$ multilayers upon annealing, J. X-Ray Sci. Technol., 1995; 5, 4, 389-395.

[13] A. Chernov, N. I. Chkhalo, M. V. Fedorchenko, E. P. Kruglyakov, S. V. Mytnichenko and S. G. Nikitenko, Study of the inner structure of $\mathrm{Co} / \mathrm{C}$ and $\mathrm{Ni} / \mathrm{C}$ multilayers prepared by pulsed laser evaporation method, J. X-Ray Sci. Technol., 1995; 5, 1, 65-72.

[14] G. M. Lamble, S. M. Heald, D. E. Sayers, E. Ziegler and P. J. Viccaro, Tungsten-carbon multilayer composition and the effects of annealing: A glancing angle extended x-ray absorption fine structure study, J. Appl. Phys., 1989; 65, 11, 4250-4255.

[15] Y. Y. Yuan, K. Le Guen, J.-M. André, C. Mény, C. Ulhaq, A. Galtayries, J. T. Zhu, Z. S. Wang and P. Jonnard, Interface observation of heat-treated $\mathrm{Co} / \mathrm{Mo}_{2} \mathrm{C}$ multilayers, Appl. Surf. Sci., 2015; $331,8-16$.

[16] Y. Y. Yuan, K. Le Guen, J.-M. André, Z. Wang, H. C. Li, J. T. Zhu, C. Mény, A. Giglia, S. Nannarone and $\mathrm{P}$. Jonnard, $\mathrm{Co} / \mathrm{Mo}_{2} \mathrm{C}$ multilayer as X-ray mirror: Optical and thermal performances, Phys. Status Solidi B, 2014; 251, 4, 803-808.

[17] Y. Y. Yuan, Characterization of physico-chemical environment of Co-based multilayer mirrors working in the soft $\mathrm{x}$-ray and EUV ranges, $\mathrm{PhD}$ thesis, 2014. https://tel.archives-ouvertes.fr/tel-01080753.

[18] X. Gao, S. Gu, Q. Gao, Y. Zou, Z. Jiang, S. Zhang, X. Wei, H. Yu, G. Sheng, P. Duan and Y. Huang, A high-resolution X-ray fluorescence spectrometer and its application at SSRF, X-Ray Spectrom., 2013; 42, 6, 502-507.

[19]B. Ravel and M. Newville, ATHENA, ARTEMIS, HEPHAESTUS: data analysis for X-ray absorption spectroscopy using IFEFFIT, Journal of Synchrotron Radiation, 2005; 12, 537-541.

[20] Refinement of the structure of the phase $\mathrm{Co}_{3} \mathrm{Mo}$, D'Alte da Veiga, L.M., Acta Crystallographica 1965; 18, 855-857. 
Tab. 1: Structural parameters of the three multilayers derived from x-ray reflectivity data measured at $0.154 \mathrm{~nm}$.

\begin{tabular}{cccccc}
\hline & $\begin{array}{c}\text { Period d } \\
\text { Sample }\end{array}$ & $\begin{array}{c}\text { Period } d \\
(\mathrm{~nm})\end{array}$ & \multicolumn{3}{c}{$\begin{array}{c}\text { Thickness/Roughness }(\mathrm{nm}) \\
( \pm 0.05 \mathrm{~nm})\end{array}$} \\
\cline { 4 - 7 } & $\begin{array}{c}\text { prior } \\
\text { annealing }\end{array}$ & $\begin{array}{c}\text { following } \\
\text { annealing }\end{array}$ & $\mathrm{B}_{4} \mathrm{C}$ & $\mathrm{Co}$ & $\mathrm{Mo}_{2} \mathrm{C}$ \\
\hline As-deposited & 4.20 & - & $3.60 / 0.56$ & $2.65 / 0.32$ & $1.55 / 0.26$ \\
$300^{\circ} \mathrm{C}$ & 4.17 & 4.18 & $3.31 / 0.56$ & $2.93 / 0.82$ & $1.25 / 0.26$ \\
$600^{\circ} \mathrm{C}$ & 4.17 & 4.13 & $2.89 / 0.54$ & $2.47 / 0.38$ & $1.66 / 0.22$ \\
\hline
\end{tabular}

Table. 2: Parameters of the first coordination shell in $\mathrm{Co} / \mathrm{Mo}_{2} \mathrm{C}$ multilayers (as-deposited, annealed at 300 and $600^{\circ} \mathrm{C}$ ) and the Co foil.

\begin{tabular}{cccc}
\hline \multirow{2}{*}{ Sample } & \multicolumn{3}{c}{ The first shell (Co-Co) } \\
\cline { 2 - 4 } & $\mathrm{N}$ & $\mathrm{R}(\AA)$ & $\sigma^{2}\left(\AA^{2}\right)$ \\
\hline as-deposited & $4(1)$ & $2.41(9)$ & $0.0125(3)$ \\
$300^{\circ} \mathrm{C}$ & $5(2)$ & $2.46(4)$ & $0.0084(4)$ \\
$600^{\circ} \mathrm{C}$ & $6(2)$ & $2.49(2)$ & $0.0089(7)$ \\
Co_foil & $6(2)$ & $2.47(4)$ & $0.0038(2)$ \\
\hline
\end{tabular}

$\mathrm{N}$ :coordination number, $\mathrm{R}$ : neighbor atoms distance, $\sigma^{2}$ : Debye-Waller factor for individual shells. Uncertainty of the last digit is given in parentheses. 